\title{
FLEXIBILIZAÇÃO DO CAPITAL NA RESERVA EXTRATIVISTA CHICO MENDES E SEU ENTORNO - O CRONÔMETRO ENTROU NA FLORESTA
}

\section{Capital Flexibilization within the Chico Mendes Extractive Reserve and its buffer zone - The chronometer entered the forest}

Juan Felipe Negret Educador Popular, Formado em Ciências Biológicas na Universidade de Brasília

Rio Branco/AC - Brasil juan_negret@yahoo.com.br

Artigo recebido para publicação em 08/09/2009 e aceito para publicação em 01/07/2010

RESUMO: A flexibilização do capital, que aqui é constatada inclusive dentro de Áreas Protegidas da Amazônia, em especifico na Reserva Extrativista Chico Mendes, é um paradigma produtivo que tem se fortalecido durante o processo de globalização. A natureza dessa flexibilização é analisada e discutem-se os impactos deste paradigma nas tradições e condições de vida das comunidades da Reserva e do seu entorno.

Palavras chave: Reserva Extrativista. Populações Tradicionais. Capitalismo. Flexibilização. Amazônia.

ABSTRACT: The capital flexibilization, which is here reported even within Amazonian protected areas, specifically in the Chico Mendes Extractive Reserve, is a productive paradigm that has strengthened during the globalization process. The nature of this flexiblization is analyzed and the impacts of this paradigm on the traditions and life conditions of communities from the Reserve and its buffer-zone are discussed.

Keywords: Extractive Reserve. Traditional Population. Capitalism. Flexibilization. Amazon. 
"Parece que a mão-de-obra just-in-time substituiu os suprimentos just-in-time...”

Manuel Castells

\section{INTRODUÇÃo}

A Reserva Extrativista (Resex) é uma categoria de Unidade de Conservação peculiar na legislação brasileira cuja matriz histórica está nas pressões do movimento social do final da década de 80 , que reivindicava um processo de reforma agrária diferenciada para a Amazônia. O objetivo primordial deste instrumento legal foi a conquista pela terra como principal meio de produção e de sobrevivência dos extrativistas. Chico Mendes afirmava nesse então: "O que nós queremos com a reserva extrativista? Que as terras sejam da União e que elas sejam de usufruto dos seringueiros ou dos trabalhadores que nela habitam..." (LÖWY, 2005, p. 12). De acordo com a legislação brasileira:

A Reserva Extrativista é uma área utilizada por populações extrativistas tradicionais, cuja subsistência baseia-se no extrativismo e, complementarmente, na agricultura de subsistência e na criação de animais de pequeno porte, e tem como objetivos básicos proteger os meios de vida e a cultura dessas populações, e assegurar o uso sustentável dos recursos naturais da unidade. (BRASIL, 2000)

Até o inicio de 2009, foram criadas em torno de 50 reservas extrativistas federais, cobrindo por volta de 10 milhões de hectares em diversos biomas do Brasil, e existem aproximadamente outros 50 pedidos de criação para novas unidades. Embora esses números sejam indicadores interessantes do sucesso do conceito das Resex, somente a sua criação e delimitação não têm conseguido satisfazer por completo as necessidades do movimento social amazônida. Uma série de dilemas tem surgido nestes últimos anos para a implementação das unidades; segundo Sevá (2002, p. 63), “... as Reservas haviam sido criadas, e só. Não haviam sido oferecidas condições mínimas de preços, de infra-estrutura, de escoamento, incentivos, subsídio, programas de saúde, transporte ou educação...”.
A luta dos movimentos sociais contra o latifúndio e a concentração de capital no meio rural amazônico deu um passo importante ao conquistar a terra como meio de produção. Mas a contradição capitaltrabalho adaptou-se às novas condições e diversos atores sociais passam a funcionar como "mercadores da natureza" (PAULA, 2005, p. 341). Estas adaptações estão fundamentadas, entre outros fatores, por uma mudança no paradigma produtivo e da organização social do trabalho: por uma flexibilização do capital.

Os ciclos da borracha iniciaram-se, como coloca Stuart Hall (2008, p. 28) em suas descrições de comunidades diaspóricas, a partir da procura de melhores condições de vida e um "retorno redentor" ao local de origem: "A pobreza, o subdesenvolvimento, a falta de oportunidades - os legados do Império em toda parte - podem forçar as pessoas a migrar, o que causa o seu espalhamento - a dispersão. Mas cada disseminação carrega consigo a promessa do retorno redentor". Porém, esse retorno, na enorme maioria dos casos, não aconteceu nem depois do primeiro ciclo, nem depois do segundo, dadas as altas taxas de exploração da força de trabalho nos seringais. A partir das décadas de 70 e 80 no Acre, o decréscimo abrupto da economia da borracha junto com a chegada e consolidação de novas formas de acumulação do capital, como a pecuária (GOMES, 2001; SEVÁ, 2002), agricultura (GOMES, 2001) e a extração de madeireira (PAULA, 2005), reestruturam a organização do trabalho e criam outras relações entre o capital e o extrativista.

Em 2003, a pecuária de corte e a pecuária de leite representaram $71 \%$ e $18 \%$ do Valor Bruto de Produção do Acre (VBP) da produção animal, e a pecuária de corte foi, no ano de 2004, responsável por $77,22 \%$ dos R\$ 195.258.940,00 recolhidos "da saída de mercadorias para outros estados do país" (ACRE, 2006, p. 148-149). Além disso, "as exportações do Estado sofreram um acentuado aumento nos últimos 5 anos, com variação média anual de $86,5 \%$, onde o setor florestal madeireiro vem contribuindo com cerca de 50\% do total." (ACRE, 2006, p. 144-145).

$\mathrm{Na}$ década de 90 , a velha ordem do seringalismo caracterizada pela relação de aviamento onde "o aviador adianta bens de consumo e alguns instru- 
mentos de trabalho ao produtor e este restitui a dívida contraída com produtos extrativos agrícolas" (ARAMBURU, 1994 apud PAULA, 2005, p. 52) reconfigura-se aos poucos: enquanto o seringueiro se apodera da terra, as figuras do Estado, do empresário e do atravessador ganham força na produção e circulação das mercadorias. Reforçam-se as relações de produção voltadas para uma readaptação ao capital mundializado, à divisão internacional do trabalho e ao capitalismo financeiro, moldando-as de acordo com os "estreitos limites da contabilidade do tempo (...) da ordem social do capital" (MÉSZÁROS, 2007, p. 42). Parafraseando Coriat (2001, p. 2): o cronômetro entrou na floresta, um cronômetro entendido como toda tecnologia de medição do tempo e de movimentos criada após o taylorismo; o autor define o cronômetro como "un instrumento político de dominación sobre el trabajo."

$\mathrm{Na}$ atual globalização que:

apresenta e representa a generalização do processo de desterritorialização do capital, com sua expansão por todos os países, sua concentração em um núcleo humano cada vez menor percentualmente, com extraordinária velocidade de movimento (...) refere-se à globalização do capital, do aumento do poder concentrado em corporações financeiras transnacionais e em Estados Centrais, que imprimem uma dinâmica coercitiva, homogeneizadora no plano cultural, profundamente excludente em relação a populações marginais e países periféricos... (LOUREIRO, 2006, p. 81-82).

O aumento extraordinário da flexibilidade e adaptabilidade possibilitadas pelas novas tecnologias contrapôs a rigidez do trabalho à mobilidade do capital. (...) A produtividade e a lucratividade foram aumentadas, mas os trabalhadores perderam proteção institucional e ficaram cada vez mais dependentes das condições individuais de negociação e de um mercado de trabalho em mudança constante. (CASTELLS, 2005, p. 350)

A flexibilização pode ser considerada uma res- posta às falhas do taylorismo, do fordismo e do toyotismo, para solucionar os ciclos de sobre-acumulação (MÉSZÁROS, 2007) e um mecanismo para dinamizar a acumulação por espoliação (HARVEY, 2005). Conclusões semelhantes são apresentadas por Mészáros (2007, p. 148), que considera a "flexibilidade" e a "desregulamentação" como os "verdadeiros obstáculos confrontados pelo trabalho no presente e no futuro próximo". Em outro estudo comparado, Negret (2001) faz uma análise da flexibilização utilizando as categorias de composição orgânica do capital, e sua composição entre capital variável (força de trabalho) e capital constante (meios de produção, maquinária etc.), coloca que o processo de flexibilização, entendido como "as mudanças nas normas e legislações laborais, da divisão técnica dos processos de trabalho e no uso da tecnologia" (NEGRET, 2001, p. 56), tende a aumentar o capital constante em relação ao capital variável na proporcionalidade do capital orgânico. Em outras palavras, a relação capitalista prioriza o investimento em meios de produção, maquinária (tecnologia) e, sobretudo capital financeiro não imobilizado, investindo cada vez menos na remuneração e qualificação da mão de obra.

Neste artigo, a flexibilização do capital será colocada em três formas: a flexibilização dos meios de produção, a flexibilização da força de trabalho e a flexibilização dos ofícios - outras formas de flexibilização como a das estruturas legais ou em termos da tecnologia da informação não serão focos deste artigo. A primeira forma, a flexibilização em termos dos meios de produção acontece nas situações quando o capitalista não possui diretamente os meios em si, mas os arrenda (ou aluga) a partir de transações com capital financeiro; podem ser arrendamentos da terra, das máquinas, dos meios de transporte e outros. A segunda forma verifica-se em contratações irregulares de mão-de-obra que desconsideram os direitos trabalhistas e a Consolidação das Leis do Trabalho (CLT), como o aumento de contratações temporárias e terceirização dos serviços - "terceirização" é frequentemente usada no Brasil; na Colômbia o mesmo processo recebe o nome de "subcontratação" (NEGRET, 2001) e nos EUA e Canadá de "subcontracted" ou "contracted-out" (KLEIN, 2005) - que não assinam as carteiras de trabalho e, consequentemente 
geram instabilidade laboral. E finalmente, a terceira forma de flexibilização, dos ofícios, acontece a partir do momento em que o trabalhador se vê obrigado a exercer mais de uma função no trabalho, a ser polivalente; significa, de certa forma, abandonar o paradigma fordista (a esteira de produção), no qual um trabalhador exerce a mesma função repetidamente durante toda a jornada. Na Era da Informação (CASTELLS, 2001) na qual impera a automatização dos meios de produção, torna-se mais rentável um único trabalhador capacitado para desenvolver a maior quantidade de tarefas possíveis.

O propósito deste trabalho é constatar e analisar a flexibilização do capital e seus reflexos junto às populações extrativistas; interessa, sobretudo, problematizar o fenômeno enfatizando seus impactos negativos na qualidade de vida e do meio ambiente. Toma-se como referência o processo da RESEX Chico Mendes: o artigo foi construído a partir de acompanhamento de eventos públicos (reuniões, oficinas, etc.), de entrevistas com moradores, colhendo impressões das comunidades envolvidas e de impressões pessoais sistematizadas em quatro anos de incursões junto aos atores da dinâmica da RESEX. Duas complementações necessárias para este estudo são: uma análise antropológica da dinâmica dos conceitos e percepções do quê significa "condições de vida" e "tempo destinado ao trabalho"; e uma complementação estatística relativa à posse dos meios de produção e à quantidade (tempo) e qualidade da aplicação da força de trabalho (tipos de ofícios).

\section{A RESEX CHICO MENDES}

A Reserva Extrativista Chico Mendes (970.000 ha) foi criada no ano de 1990 abrangendo seis municípios do Estado do Acre. Segundo o Plano de Manejo aprovado em dezembro de 2006 (IBAMA, 2006a), moravam naquele ano na Reserva quase 2000 famílias, organizadas em 15 Associações, 5 Cooperativas e 54 Núcleos de Base; hoje em dia a população aumentou, assim como o número de organizações de base existentes. Inicialmente, a principal fonte de renda dessas comunidades foi a exploração de borracha, mas as atividades extrativas têm decrescido com o passar do tempo. Atualmente, a castanha-da-amazônia tem um papel importante, mas a prestação de serviços e a criação de gado têm crescido na composição da renda familiar. No SNUC (BRASIL, 2000) permitiu-se somente "a criação de animais de pequeno porte", mas já no plano de manejo (IBAMA, 2006a), a norma 36 do plano de uso estabelece que "A criação de grandes animais, como gado, será permitida até o limite máximo de $50 \%$ da área da colocação destinada para atividades complementares".

A possibilidade da exploração madeireira dentro das RESEX no Acre é cada vez mais próxima da realidade e em outros Estados do país essa atividade já existe. O sistema de difusão e propaganda do próprio Governo do Estado (GUIMARÃES JUNIOR, 2007), junto com uma série de empresários madeireiros e a ação de algumas organizações de assessoria e ONGs, têm contribuído para a elaboração e pressão no licenciamento de alguns planos de manejo madeireiros, comunitários e empresariais, nos municípios onde se situa a reserva. Aprovados previamente pelo conselho deliberativo da Reserva espera-se que no máximo em 2010 esses planos já tenham sido licenciados pelo IBAMA.

No município de Xapuri, o Governo do Estado, construiu uma fábrica de tacos para piso que gera uma enorme demanda de matéria prima e pressão sobre as comunidades: a intenção é supri-la também com madeira da Reserva. Segundo o ZEE (ACRE, 2006, p. 144):

O componente florestal do Programa de Desenvolvimento Sustentado II, com recursos do BNDES, prevê importantes investimentos industriais na região de Xapuri, com o estabelecimento de uma fábrica de piso que possui capacidade instalada para o consumo de aproximadamente $40.000 \mathrm{~m} 3$ de madeira/ano. Este volume representa $295 \%$ da atual produção de manejo florestal da Regional e $1.500 \%$ da produção comunitária (...) Apesar da fábrica possuir uma estratégia de abastecimento diversificada, não dependendo exclusivamente da produção comunitária, não se pode negligenciar o potencial para a conservação e melhoria de qualidade de vida dos moradores da RESEX, assim como seus potenciais riscos re- 
lacionados a adoção do Manejo Florestal na RESEX.

Durante os 18 anos de vida da unidade, houve uma guinada significativa no discurso de várias lideranças e moradores da RESEX em torno da questão madeireira. No primeiro Plano de Utilização (IBAMA, 1995), o documento afirmava categoricamente, na norma de uso número 12, que "Não será permitido o comércio de madeiras, na Reserva Extrativista". A literatura já há algum tempo debate sobre a sustentabilidade da madeira: "A madeira é outro produto extrativo não considerado (nas suas análises) por ser insustentável" (SCHWARTZMAN, 1994). Mas com a ascensão do Governo da Floresta no Estado do Acre e a aprovação da Lei do SNUC em 2000, setores do Ministério do Meio Ambiente (MMA, 2002, p. 68), por exemplo, passaram a afirmar que "Embora resistida por muito tempo, não existem razões válidas para excluir a exploração madeireira nas Reservas Extrativistas, sempre que praticadas através de procedimentos de manejo que assegurem a sustentabilidade".

A aprovação da Lei de Gestão das Florestas Públicas e Concessões Florestais, apoiada por setores do movimento social do Estado do Acre, inclusive pela ex-Ministra acreana Marina Silva, indica esse redirecionamento político-discursivo também no nível de uma política federal, muito embora a técnica ainda não tenha sido devidamente avaliada em um ciclo de corte completo, geralmente 30 anos. O próprio Conselho Nacional de Seringueiros (CNS) passa por modificações no discurso e na prática. Em 1993, em um documento oficial, Diretrizes para um Programa de Reservas Extrativistas na Amazônia afirma-se que “... o CNS se posiciona contra a exploração dos recursos madeireiros." (PAULA, 2005, p. 247-248). Mas já em 1995, algumas das lideranças passam a reconsiderar essa posição em depoimentos pessoais:

Eu acho que no caso da Amazônia, nas reservas extrativistas, o caso da borracha e da castanha é apenas um pingo d'água em cima das riquezas que se observa lá. Eu vejo algumas delas como importantes, como é o caso da madeira. E aí, é uma questão que nós do Conselho estamos bastante convencidos sobre a ativida- de madeireira. (PAULA, 2005, p. 334).

Como reflexo e evidência desses redirecionamentos, na revisão do Plano de Utilização da RESEX Chico Mendes realizada em 2006, a nova norma número 28 contradiz o plano de 1995 citado acima, permitindo agora o comércio de madeiras e estabelecendo que: "Para que haja comercialização de madeira por parte dos moradores da Reserva é obrigatório o Plano de Manejo Florestal Sustentável de Uso Múltiplo Comunitário - PMFSComunitário, aprovado pelo IBAMA com anuência do Conselho Deliberativo"(IBAMA, 2006a).

Porém, longe de ser um consenso, a atual diretoria do STR de Xapuri é contrária ao manejo de madeira na reserva. Entre o conjunto dos moradores da RESEX há uma complexa dinâmica de posições e discursos quanto às vantagens (econômicas, sociais e ambientais) do manejo: algumas de fato querem o manejo, outras querem somente viabilizar o ramal de acesso às colocações, outras pretendem atrair políticas públicas como saúde e educação, outras são contundentemente contrárias à exploração madeireira e há também quem, por conveniência ou desconhecimento do assunto, não se posiciona no processo.

\section{A FLEXIBILIZAÇÃO NA RESEX CHICO MENDES}

As três formas anteriormente descritas desta flexibilização podem ser identificadas na região do Alto Acre, região onde está localizada a Reserva Extrativista Chico Mendes, e serão discutidas nesta seção. Essa identificação pode ser feita a partir da análise sobre os dois capitais mais significativos em termos de recente avanço na região: a criação de pecuária de corte e a exploração de madeira via manejo florestal. O primeiro já hoje em dia pode ser identificado dentro da RESEX. O manejo madeireiro, porém, como já foi colocado, ainda não é uma realidade concreta, embora seja um cenário muito provável para os próximos anos. De qualquer maneira, as formas descritas de flexibilização em relação ao processo produtivo do manejo florestal madeireiro são bastante evidentes em regiões vizinhas à RESEX dentro do raio de dez quilômetros que delimitam o seu entorno, sobretudo nos Projetos de Assentamento Extrativistas 
(PAEs) Equador, Chico Mendes (Mais conhecido por PAE Cachoeira, assim referido ao longo do texto) e São Luiz do Remanso, e são encontradas também em RESEX de outros Estados da Amazônia onde é realizado o manejo comunitário madeireiro (MEDINA e POKORNY, 2008).

\section{A Flexibilização dos Meios de Produção}

O aluguel (ou arrendamento) das áreas desmatadas na RESEX Chico Mendes por frigoríficos, fazendeiros ou moradores da cidade para a criação de pecuária de corte e ampliação do rebanho é uma prática já constatada (GOMES, 2001) que, embora não seja válida para todo o rebanho bovino, tem ganhado uma expressiva frequência. Esta é uma prática informal - por muitas vezes, além de informal, a atividade é também ilegal, em termos ambientais quando o desmatamento excede o Código Florestal - debate intenso ultimamente - e/ou a atividade fere o SNUC, e em termos trabalhistas, uma ver que não existe nenhum tipo de contrato ou registro público entre os locatários e os moradores, e quando emprega-se mão-de-obra infantil e reduz a frequência das crianças na escola por exemplo. O arrendamento mencionado constitui a flexibilização da terra em si, como meio de produção. Por meio desse aluguel, o locatário não arca com as despesas de compra da terra e mantém uma quantidade maior de capital móvel (capital-dinheiro). Em casos de grandes pecuaristas, cuja posse de cabeças de gado extrapola a capacidade limite de suas fazendas, a alternativa do arrendamento torna-se bastante rentável e assegurada em alguns casos, até com salvaguarda via corrupção em alguns órgãos oficiais.

No ato do aluguel, o pecuarista terceiriza e transfere a responsabilidade legal pelas infrações ambientais e evita também qualquer pagamento de impostos ou tributos pelo uso da terra, já que, por lei, a RESEX é uma concessão de uso às populações tradicionais. Desta forma, os custos que o capitalista teria em termos de contribuições fiscais ao Estado são descontados das planilhas financeiras, mas esses mesmos valores não são agregados ao pagamento dos produtores dentro da RESEX, gerando mais lucro e evadindo a receita do Estado; assim, a flexibilização contribui para a concentração de renda e para o enfraquecimento das estruturas estatais e de organização social das comunidades.

No caso da exploração madeireira é possível estudar a zona de amortecimento da RESEX e analisar, por exemplo, o Projeto de Assentamento Agroextrativista (PAE) do Seringal Equador, próximo da RESEX Chico Mendes. No Relatório de Auditoria da Certificação deste PAE (IMAFLORA, 2007, p. 4), coloca-se que:

Tendo em vista a implementação do sistema de arraste e transporte mecanizado na exploração ocorrida em 2005, a auditoria teve como foco a análise do cumprimento das ações corretivas estabelecidas na avaliação de 2005 e as mudanças decorrente da adoção do novo sistema de arraste e transporte.

Assim, em termos da flexibilização na cadeia produtiva da madeira, além de apontar a flexibilização da terra, é possível fazer a análise em termos das máquinas necessárias para a produção. $\mathrm{O}$ transporte mecanizado ao qual se refere o texto são máquinas que não pertencem ao produtor rural, mas sim ao governo ou aos empresários, o que dialoga diretamente com o conceito de capital de MÉSZÁROS (2002, p. 67), como sendo o trabalho, o "meio de produção alienado, incorporado à propriedade privada ou estatal", e evidencia o papel repressor e explorador que o Estado-Nação assume historicamente (MÉSZÁROS, 2007: 61). O mesmo Relatório de Auditoria coloca que no arraste e transporte a execução foi realizada por contratos terceirizados via a Secretaria de Florestas do Acre (SEF) e pela Cooperativa dos Produtores Florestais Comunitários (COOPERFLORESTA), uma cooperativa criada pela própria SEF para gerenciar o manejo florestal comunitário madeireiro, que reúne grande parte dos manejos dessa natureza no Estado do Acre. Geralmente, a construção de estradas, pontes e pátios também é realizada por contratos similares, gerenciados pelo próprio governo e/ ou as empresas madeireiras. Uma porcentagem mínima de todos esses capitais passam pelas mãos das comunidades envolvidas, como analisado por Medina e Pokorny (2008). 
Para ilustrar o grau de intensificação da flexibilização da terra, no Projeto de Assentamento Extrativista Porto Dias, na safra de 2008, um empresário terceirizou a produção de 40 famílias, comprando madeira a R \$ 500,00 o hectare; a flexibilização gerou até a substituição das unidades de medida e dos parâmetros nos negócios. Comparando com a extração não terceirizada comunitária $\left(10 \mathrm{~m}^{3}\right.$ por hectare), a exploração teve o triplo da intensidade em termos de volume ( $27 \mathrm{~m}^{3}$ por hectare), enquadrando-se já na categoria de Manejo Pleno, categoria de maior intensidade, segundo a Instrução Normativa 05 do IBAMA que regulamente o manejo madeireiro (IBAMA, 2006b). Embora a comunidade não tenha tido quase trabalho, ganharam irrisórios $\mathrm{R} \$ 18,00 / \mathrm{m}^{3}$.

\section{A Flexibilização da Força de Trabalho}

As práticas de arrendamento das colocações para criação de gado e a prática da terceirização das máquinas constituem, além de formas de flexibilização dos meios de produção, formas de flexibilização da força de trabalho do detentor da terra, no caso o agroextrativista. Paula (2005) já identificava primórdios dessas novas relações laborais, ainda no inicio da década de noventa, na Usina Chico Mendes de Xapuri, gerenciada pela Cooperativa AgroExtrativista de Xapuri (CAEX), que era destinada ao beneficiamento da castanha.

Embora a carga de trabalho para a criação de gado seja relativamente pequena (se comparada à lavoura, por exemplo) e os seus custos relativamente baixos, o produtor que aluga a sua colocação está também vendendo sua força de trabalho para cuidar dos animais. Em geral, a atividade pecuária representa um baixo nível de geração de empregos, se comparado à lavoura temporária e à lavoura permanente (SEVÁ, 2002) e, geralmente, essas atividades são executadas pela figura masculina. $O$ contingente de mão-deobra flexibilizado das RESEX, pelo seu baixo custo de remuneração, mantém o seu boi competitivo no mercado e, considerando que o mercado das carnes é bastante estável (pois sempre há compradores disponíveis a pagar à vista), a flexibilização representa uma oportunidade de aumentar os lucros e a competitividade dos fazendeiros, frigoríficos e moradores da ci- dade. Dedicar-se à criação de gado representa menos trabalho que cortar seringa (SEVÁ, 2002); embora o boi represente uma baixa rentabilidade, representa também uma alta liquidez e um baixo risco no negócio, caracterizando uma poupança para o/a morador/a da reserva.

Já a madeira comunitária, segundo Medina e Pokorny (2008, p. 207), apresenta "rendimentos modestos" e "riscos relativamente altos". O locatário que arrenda pastos na RESEX tampouco paga os tributos laborais (INSS, ISS, FGTS, etc...), nem licença maternidade, ou décimo terceiro, nem qualquer forma de seguro de saúde ou seguro contra acidentes, pois não existe nenhum vínculo trabalhista oficial (contrato ou carteira assinada) com o morador da reserva. Além disso, o arrendatário aciona a mão-de-obra (assim como o meio de produção) só quando lhe é conveniente enquanto negócio, poupando custos de pessoal quando não lhe for interessante.

Podemos continuar a análise com o exemplo do PAE Equador, pois o Relatório de Auditoria da Certificação já citado (IMAFLORA, 2007, p. 4) coloca que "as atividades de arraste e de transporte foram realizadas por trabalhadores terceirizados". No texto afirma-se ainda que a fase pré-exploratória, sobretudo elaboração do inventário e elaboração do POA, foi executada por agentes florestais terceirizados via a Cooperativa dos Trabalhadores em Atividades Florestais das Regiões do Baixo e Alto Acre (COOTAF), que é uma cooperativa de serviços, composta por agentes florestais comunitários, mas que passa por grandes dificuldades de implementação e de gestão; hoje em dia, embora esteja com sérias dificuldades, continua funcionando timidamente. Para a fase exploratória, as atividades do corte como a de motosserristas foram executadas pela própria comunidade, e geralmente o pagamento foi realizado por produto.

A safra da madeira segue um ciclo anual, dependendo esta basicamente da intensidade das chuvas e da acessibilidade dos ramais. Os trabalhadores são pagos por alguns meses e recebem por produto ou por diária em vez de receberem um salário mensal com carteira assinada. O manejo tem deixado poucos recursos para as comunidades; no PAEs Cachoeira e Equador quem tem ganhado mais são os "mobilizadores comunitários", pagos pelo governo, e os mo- 
tosserristas que são pagos em até $\mathrm{R} \$ 5,00$ por metro cúbico serrado, ou então em até $\mathrm{R} \$ 100,00$ por diária (Segundo liderança entrevistada em 02/10/08). Medina e Pokorny (2008, p. 209) afirmam, em uma análise financeira detalhada que "é, portanto, coerente pensar que outras formas de uso da terra oferecem melhores remunerações que o manejo florestal".

No caso dos manejos comunitários do Acre, onde a maioria tem sido incentivada a adquirir o certificado FSC, um dos papeis aparentemente papeis positivos desta certificação por auditoria seria o incentivo a que as empresas estejam com seus encargos trabalhistas em dia e que garantam, a princípio, todos os direitos aos trabalhadores. Na prática, tem-se incentivado o contrário e sabe-se que, estes critérios recorrentemente questionados por empresários, são relegados a um segundo plano e às vezes abandonados no momento em que as finanças da empresa correm mal. Historicamente, a certificação é um instrumento prioritariamente para satisfação do mercado; uma narrativa sobre a origem dos selos e de seus efeitos sobre a organização do trabalho, desde o final do século XIX, pode ser encontrado em Coriat (2001, p. 12-16).

Ambos os processos de flexibilização, tanto âmbito da pecuária e no âmbito da exploração madeira, podem ser analisados sob a conversão de lucro em renda do solo (MARX, 2001, p. 576), onde “... los verdaderos agricultores son obreros asalariados, empleados por un capitalista, el arrendatário, el cual no ve em la agricultura más que un campo especial de explotación del capital, de inversión de su capital em uma rama especial de producción". Apesar da conquista da terra, os extrativistas continuam reféns da exploração capitalista, da lógica de mercado e do capital desterritorializado.

\section{A Flexibilização dos Ofícios}

A identidade da classe trabalhadora rural amazônica, assim como descreve Thompson (2004, p. 10) para a classe operária inglesa, está constantemente no processo de fazer-se, de reestruturar e reconstituir a si mesma, adquirindo e abandonando tradições: “A classe acontece quando alguns homens, como resultado de experiências comuns (herdadas ou partilhadas), sentem e articulam a identidade de seus interesses entre si...".
A partir da queda da economia da borracha, o discurso do "uso múltiplo" começa a ocupar um lugar significativo nas formas alternativas para a geração de renda e complementação da economia familiar. No inicio da década de noventa, Allegretti (apud ARNT, 1994) coloca que o qualificativo 'extrativista' exerce uma espécie de "camisa de força" frente à realidade amazônica, que é mais múltipla do que o nome pretende expressar. Percebe-se que a expressão "uso múltiplo" ainda não está presente literalmente, mas o a realidade do trabalhador rural amazônico da década de 90 já contemplava a idéia de atividades econômicas diversificadas e complementares, múltiplas.

Devem ser diferenciadas, porém, duas dimensões do "uso múltiplo" e dessa flexibilidade/ambivalência no que diz respeito aos ofícios executados por essas populações tradicionais, inclusive as residentes na RESEX Chico Mendes - cabe ressaltar o caráter didático desta divisão, que ajudará no sentido de evitar confusões futuras entre "uso múltiplo" e polivalência nos ofícios. A primeira diz respeito ao uso múltiplo na econômica doméstica, prioritariamente voltada para o autoconsumo (CALAÇA apud PAULA, 2005, p. 93), característica das populações caboclas da Amazônia, que sobrevivem de vários recursos da floresta, seja colhendo, seja plantando (LIMA apud ADAMS, et al, 2006). Mas existe também a dimensão do uso múltiplo como atividade econômica de mercado, que é igualmente necessária para subsistência das famílias, e que pode estar constituída de produtos florestais (como a castanha, copaíba, borracha, madeira, peixe, etc...) ou podem ser produtos agrícolas de produção em pequena escala (como farinha de mandioca, galinhas ou o próprio gado). Estes produtos geralmente são comercializados, com o fim de adquirir outras mercadorias como açúcar, café, pilhas, eletrodomésticos e instrumentos de trabalho, além de outros bens, e com o fim de aumentar a renda monetária para melhorar também as condições de vida dessas mesmas famílias. Nas últimas décadas, como já foi sinalizado, algumas comunidades começaram a prestar serviços vendendo sua força de trabalho por vezes de forma assalariada e outras vezes pagas por produto; e algumas famílias começaram prestar serviços (professores, agentes de saúde, etc..), a receber pensões, seguros e formas de assistência estatal, para 
ajudar a compor também a economia monetária. Às categorias de economia doméstica e economia monetária pode-se atrelar um paralelo com as categorias de "valores-de-uso" e "valores-de-troca" (MARX, 2008) e as categorias "terre-matiére" (terra-matéria) e "terre-capital" (capital investido e incorporado na terra) (MARX, 2001).

Percebe-se, pelo histórico e pelas experiências existentes, que é bastante difícil atingir um bom desempenho em várias cadeias produtivas do uso-múltiplo de mercado ao mesmo tempo, uma boa alocação qualificada e múltipla do trabalho em segmentos diferenciados; e por isso percebe-se a tendência em muitas unidades familiares de focar uma determinada atividade e complementá-la com as demais. Esta priorização da produção pode variar de acordo com os aspectos de distribuição heterogênea dos recursos naturais, que mudam de município para município (por exemplo, o município de Assis Brasil (Acre) não possui castanhais e tem tido as maiores produções de borracha FDL, enquanto o município vizinho, Brasiléia, comparativamente, possui grandes populações de castanheiras), e da sazonalidade de certas cadeias produtivas.

Por um lado, trabalhar uma única cadeia produtiva facilita o processo de assimilação das informações e reduz também a quantidade de tarefas diversificadas. Por outro lado, a diversificação da produção gera uma segurança frente à volatilidade dos mercados, sempre que se opte por uma diversificação cadeias estáveis: é, porém, essa mesma estabilidade e liquidez que leva a muitos a optarem pelo boi em detrimento, por exemplo, da madeira, que depende do bom-humor dos compradores de São Paulo e do exterior, em uma complexa trama de mercado. Segundo um produtor do PAE Cachoeira (Entrevistado em 02/10/08) associado à COOPERFLORESTA, a madeira "não é um produto, é mais de vinte e tantos produtos (...), a cooperativa tem que se virar para vender todas".

O fenômeno desse primado por uma ou outra cadeia produtiva pode ser constatado de forma geral em várias regiões da Amazônia: no estuário amazônico, onde o foco da produção está no açaí (BRONDIZIO apud ADAMS et al, 2006); nas comunidades insulares do médio-baixo Amazonas, onde o foco é a pesca comercial (CASTRO apud ADAMS et al, 2006); na
RESEX Rio Preto-Jacundá, no Estado de Rondônia, onde a principal cadeia é a farinha de mandioca, e a própria madeira é secundária para as famílias; e em Mamirauá, onde a pesca é o foco da produção, mas pode variar de ano para ano de acordo com as condições climáticas e ambientais (LIMA apud ADAMS et al, 2006). A Central de Cooperativas Comunitárias do Acre - COOPERACRE tem focado as suas ações na cadeia produtiva da castanha, e os outros produtos do uso-múltiplo (como copaíba, andiroba, vinho de jatobá, etc...) são carregados em segundo plano e em segundas prioridades.

Em geral, essas atividades priorizadas para a economia monetária de uso-múltiplo (Açaí, peixe, farinha e castanha) estão pautadas por relações espaçotemporais atreladas aos tempos da floresta, como condições climáticas, biologia das espécies ou relações ecológicas: "A gente sai hora que quer e volta à hora que quer, mas se deixar pra mais tarde, a cutia começa a comer a castanha. (...) O roçado a gente faz na hora extra, só o arroz que a gente tem que apanhar logo" (Produtor entrevistado em 02/10/08). Assim, as atividades de pesca, colheita e cultivo estão relacionados com o próprio tempo dos peixes, a chuva, a temperatura e intensidade do sol.

Novas identidades e novas complexas construções temporais, porém, desenvolvem-se a partir do novo regime de ofícios incentivados pelos dois capitais em questão. No processo da pecuária de corte, embora o mercado de carne bovina seja hoje em dia bastante estável e garanta liquidez, aquele produtor que migrou do nordeste para assumir basicamente o ofício único de seringueiro e que passou posteriormente a exercer atividades agro-extrativistas (PAULA, 2005), vê-se hoje pressionado pelo mercado a produzir um boi que seja competitivo: precisa aprender técnicas e habilidades de médico veterinário para vacinar o gado (no caso do Acre, em parceria com o Governo Federal, existe uma forte campanha contra a Febre Aftosa desde o primeiro governo do Jorge Viana), a realizar as cirurgias para capar os machos para o melhoramento genético do rebanho, a construir as benfeitorias apropriadas para o rebanho, dar sal aos bois, ser vaqueiro e "tocar a boiada", fazer os cercos e os "corredores" nos ramais para evitar acidentes dos veículos, e assim por diante. 
No caso madeireiro, o impacto nos ofícios acontece de forma heterogênea de acordo com as diversas funções que são exigidas. Alguns produtores, por meio do regime de terceirização, dispensam o envolvimento em várias fases da produção o que é em si própria uma mudança radical nas relações de produção: "Nem todos se envolvem no processo, o técnico vem e faz tudo", coloca um morador do PAE Cachoeira (Entrevistado em 02/10/08); e alguns técnicos inclusive brincam: "o seringueiro só precisa ficar deitado na rede...". Um segundo produtor do PAE Equador mais diretamente envolvido colocou "A castanha é o que mais dá trabalho, seguido do roçado; a castanha dá três meses de trabalho, o manejo um" (Entrevistado em 02/10/08). E um terceiro, novamente do PAE Cachoeira, (Entrevistado em 03/10/08), disse até que, certa vez, os técnicos entraram na sua colocação sem avisar e, quando percebeu, a madeira já havia sido levada e, além de ter sido arrastada por onde ele não queria, nem sequer pôde conferir a quantidade de madeira que foi carregada.

As transformações identitárias e as principais mudanças nas relações de produção são mais facilmente notadas para novas categorias de trabalho geradas pelo manejo madeireiro, como os agentes florestais, os motosserristas e os mobilizadores comunitários. Mudam as formas de relacionar-se com a produção, com a jornada de trabalho e com as novas formas de remuneração, que passam a ser pautadas pelo relógio, e não mais pelo primado do tempo da floresta, como o "tempo das cutias". O agente florestal recebe as pressões de ser ao mesmo tempo um bom mateiro e inventariador para realizar os "inventários florestais 100\%", um bom bussoleiro, um bom medidor de toras (inclusive para não ser enganado e receber por menos madeira do que realmente vendeu), e vê-se pressionado a atender as ações corretivas (CARs) que impõem as organizações de auditoria, no caso das áreas de certificação comunitária. O motosserrista vê-se pressionado da mesma forma por um mercado extremamente exigente que não está disposto a pagar um preço diferencial entre madeira empresarial e comunitária, e despreza qualquer defeito nas toras; o mobilizador comunitário tem agora que cumprir metas que o novo patrão fixa para persuasão de mais famílias para o manejo. Segundo Medina e Pokorny: a verticalização da produção aumentou o valor de venda do produto final, mas também aumentou os custos de produção em maior proporção, limitando a receita final (...) com o arranjo mais complexo é mais difícil manter a eficiência nas diferentes etapas de produção" (2008, p. 210); e "aumentar a produtividade significa aproximar as formas de trabalho do modelo empresarial, porém, que os sistemas sejam cada vez menos adaptados às características de gestão por produtores familiares (2008, p. 203).

\section{O CAPITAL GLOBALIZADO, A FLEXIBILIZAÇÃO NO ACRE E NA RESEX CHICO MENDES}

A expansão da acumulação capitalista pelo globo e seus impactos diretos nos recursos naturais obriga a humanidade a posicionar-se proativamente em relação às mudanças climáticas e ao esgotamento desses recursos. Somente o esforço de reduzir as pressões não é suficiente: a capacidade de resiliência dos ecossistemas não consegue mais manter a própria integridade; o modo de produção excede, estruturalmente, a capacidade limite do planeta. Estas condições históricas têm gerado duas interpretações e dois projetos diferentes de sociedade: a necessidade inadiável de superação do capitalismo como colocado em Para Além do Capital de Mészáros (2002) e Ecologia e Socialismo de Löwy (2005), ou a necessidade de releituras capitalistas que realizem a valoração desse passivo ambiental, como o Capitalismo Natural de Hawken et al (1999) e a Eco-Economia de Brown (2003), entre outras.

Enquanto estas releituras insistem em modelos de redesenho dos sistemas (redesign e/ou ecodesign) que reduzam o desperdiço e aumentem a eficiência/ rendimento do uso dos recursos naturais, Löwy (2005, p. 55) é enfático ao colocar que os meios de produção não são neutros e Mészáros (2002, p. 96) rejeita essa mesma neutralidade para o 'mecanismo de mercado'. Tanto Hawken et al (1999) como Brown (2003) são obras extremamente ergonômicas, que carecem de análises estruturais na macro e microeconomia. Em uma crítica a Hawken et al (1999) e seus semelhantes, Novicki (apud LOUREIRO, 2007, p. 140) argumenta 
que essas abordagens tecnicistas tendem a "privatizar o lucro", "socializar a culpa" e "enfatizar os limites físicos (...) desconsiderando os limites sociais ao desenvolvimento sustentável", tese facilmente evidenciada na deslocada frase: "Hoje em dia, não é o número de pesqueiros que restringe o nosso progresso contínuo, e sim a diminuição do número de peixes." (HAWKEN et al, 1999, p. 3).

A economia não é uma ciência que trata somente dos objetos e das mercadorias: a economia trata, sobretudo, das "relações entre pessoas e, em última instância, de relações entre classes, relações que estas que estão sempre ligadas a coisas e que geralmente aparecem como coisas" (ENGELS apud LUKÁCS, 2003, p. 87). O trabalho deve ser entendido como mediador do metabolismo da sociedade com a natureza (FOSTER, 2005), e a natureza compreendida nas dimensões do valor-de-uso e do valor-de-troca (MARX, 2008); é um erro considerar toda a natureza (o ser humano, também incluído) unicamente como valor-de-troca, ou seja, em mercantilizá-la. Sem estas premissas, reforçadas pelas várias razões apresentadas por Loureiro (2007, p. 18-27), sobre a pertinência da tradição crítica para as análises socioambientais, qualquer exercício econômico, aprofunda o ciclo vicioso da acumulação capitalista e agrava a crise socioambiental ao invés de construir alternativas ecologicamente viáveis e socialmente justas. Em 1875, Marx colocou na Crítica ao Programa de Gotha que "A natureza é a fonte dos valores de uso (que são os que verdadeiramente integram a riqueza material!), nem mais nem menos que o trabalho, que não é mais que a manifestação de uma força natural, da força de trabalho do homem.". A acumulação e a contradição capital/trabalho, extendida para capital/natureza, são uma realidade estrutural e não passíveis de resolução por meio de simples acordos individualizados de "responsabilidade empresarial".

Nos últimos anos, um novo ciclo de acumulação na Amazônia está sendo preparado, primeiramente, por meio de um conjunto de marcos legais como a Lei $\mathrm{N}^{\circ} 11.105 / 05$ de Biossegurança que permite o uso de transgênicos; a Lei $N^{\circ} 11.284 / 06$ de Gestão de Florestas Públicas que terceiriza a fiscalização das áreas de floresta para o capital privado e inicia a fragmentação das agencias ambientais, criando o Servi- ço Florestal Brasileiro; a Medida Provisória 366/07 que divide do IBAMA em dois institutos diferentes; a Medida Provisória 422 de 2008, a chamada "MP da Grilagem" e os reiterados ataques ao Código Florestal, entre outros. Em segundo lugar, o ciclo está sendo viabilizado por uma série de obras de infra-estrutura incluídas no Programa de Aceleração do Crescimento e nos programas de Integração Sul-Americana (a exemplo do IIRSA), como o asfaltamento da Rodovia Cuiabá-Santarém (BR 163), o asfaltamento da Estrada Interoceânica (BR 317), as Usinas Hidrelétricas do Rio Madeira, os gasodutos Urucum - Manaus e Urucum - Porto Velho e os projetos de prospecção de petróleo.

Este ciclo de acumulação tem se alimentado inclusive de iniciativas piloto do Estado do Acre; a Lei de Gestão de Florestas Públicas embasa-se tecnicamente nas experiências ("laboratórios") de manejo madeireiro comunitário da Floresta Estadual do Antimary e dos Projetos de Assentamento. Conciliações com o capital têm sido realizadas, tanto no setor madeireiro quanto pecuarista, inclusive com tímidos esforços de regulamentação da produção e do mercado - majoritariamente processos de certificação por auditoria. O resultado têm sido espoliação e sobreacumulação por meio das diversas formas de flexibilização.

E sob a mesma ótica, poderá acontecer na expansão do capital sucroalcooleiro e de biodiesel. Já é possível ver canaviais sendo plantados em alguns dos municípios do Acre onde está localizada a RESEX Chico Mendes: a Usina Álcool Verde no município de Capixaba, liderada pelo Grupo Farias e a empresa Brasil Eco-Diesel que assinou convênios com o Governo do Acre para a instalação de usinas. A proliferação dos cultivos de cana provavelmente será uma ameaça à conservação e, de acordo com as constatações sobre a flexibilização no processo produtivo da cana de açúcar em Negret (2001), trará consigo um reforço às formas de flexibilização já evidenciadas no Estado.

Cabe ainda colocar-se que o paradigma da produção flexibilizada permeia também o setor terciário, dentro de organizações de assessoria, ONGs e no governo, onde uma boa parte da assistência técnica tem trabalhado via contratos temporários (por exemplo, 
via PNUD-ONU). Indiretamente, essas organizações podem ser consideradas difusoras da terceirização e da flexibilização também no meio rural.

Sendo no setor primário, secundário ou terciário, sendo empresarial ou governamental, todos os processos de difusão da flexibilização não deixam de ser formas de acumulação por espoliação (HARVEY, 2005): há uma inicial inversão de capital que gera uma sobreacumulação, que à sua vez geram um aumento nas taxas de lucro na produção e distribuição, mas que são seguidas por uma desvalorização das mercadorias e da mão-de-obra, que enfraquecem o controle social dos processos produtivos da RESEX e que, na verdade, são formas de privatização, mercantilização e dominação, que aumentam as taxas de exploração sobre as populações tradicionais. No final, os investimentos do capitalista retornam a ele próprio e, caso necessário, é possível deslocar o capital financeiro e reiniciar o ciclo em outro local.

Analisando o processo produtivo, a partir do referencial sobre as quatro fases de realização da mercadoria (MARX, 2005) — produção, circulação, distribuição/troca e consumo - , a concepção da categoria das RESEX no final da década de 80 significou, e ainda significa a cada decreto de criação de uma nova Reserva, um importante avanço em termos da apropriação dos principais meios de produção (a terra e a floresta), consequentemente, um avanço na reforma agrária e na soberania da primeira fase de realização das mercadorias. Em geral, a maioria dos estudos sobre RESEX colocam que o atual desafio das unidades é avançar na consolidação das outras partes da cadeia produtiva, na comercialização dos produtos florestais e sensibilizando consumidores conscientes que adquiram os produtos ambientalmente corretos; mas não só isso: é preciso avançar no controle social de todas as fases. É necessário levar em consideração, porém, que as formas de avanço do capitalismo por meio da flexibilização estão na verdade retomando os seringais, transformando-os em meros quintais de produção de commodities e induzindo retrocessos no empoderamento e controle que, inclusive, as comunidades locais ganharam sobre a fase de realização da produção.

\section{A FLEXIBILIZAÇÃO, MUDANÇAS NO “TRADI- CIONAL", A QUEDA DAS CONDIÇÕES DE VIDA E A QUEDA NO STATUS DE CONSERVAÇÃO}

Constatar a flexibilização na RESEX Chico Mendes permite realizar um conjunto de correlações entre princípios, valores e procedimentos que lhe são intrínsecos. Uma série de estudos têm indicado uma correlação direta entre o estabelecimento da flexibilização e a queda das condições de vida dos trabalhadores no Brasil (NEGRET, 2001) e em outras partes do mundo (CORIAT, 2001; KLEIN, 2005; CASTELLS, 2005; e MÉSZÁROS, 2007). Da mesma forma, constatam-se correlações com a queda da participação dos movimentos sociais nos processos decisórios e com um crescente enfraquecimento dos sindicatos, enfatizando, sobretudo, o papel das contratações de mãode-obra terceirizada, que geralmente não é sindicalizada, nem organizada. E, de fato, é comum ouvir em inúmeros espaços que o movimento social do Acre tem se enfraquecido nos últimos anos, entre outras causas, ademais dos processos citados acima, pela cooptação de lideranças e das organizações de base.

No caso do manejo comunitário madeireiro do Acre, alguns produtores rurais dos PAEs tem adquirido lesões na execução das atividades de manejo florestal, como desvios de coluna vertebral por carregamento das toras de madeira (caso de uma liderança do PAE Porto Dias, que foi atuante na Associação Seringueiro Porto Dias - ASPD) e como perda do dedo opositor no uso da motosserra (caso de outro produtor que foi coordenador do manejo); houve inclusive, caso de morte, por falta de equipamentos de proteção. Mesmo sendo poucos em número, este tipo de acidentes laborais não possuem qualquer garantia nem seguro ou qualquer tipo de compensação, seja ela privada ou estatal. Nestas situações, dificilmente pode-se afirmar que há alterações positivas nas condições de vida dos trabalhadores.

A flexibilização dos ofícios e a pluriespecialização têm também sido associadas a uma perda da identidade profissional (NEGRET, 2001) e, em geral, as atividades tradicionais ao redor do mundo têm sido colocadas como categorias de emprego pouco estáveis. Segundo Thompson (2004, p. 198) “... tradições estão encarnadas não só em idéias, mas em pessoas.”;

Sociedade \& N atureza, U berlândia, 22 (2): 373-390, ago. 2010 
e os processos de racionalização da produção como o taylorismo, o fordismo e o toyotismo produzem formas de controle do trabalho, do tempo e da interação entre os trabalhadores, que impossibilitam modos de produção mais livres (CORIAT, 2001), que caracterizam as atividades tradicionais amazônicas. De fato, constata-se em toda a RESEX uma redução na ocorrência dos adjuntos ou mutirões, trabalhos coletivos nos quais as comunidades se juntam para colaborar com aquela família que está precisando de ajuda para uma determinada tarefa, seja colher um ou outro produto, abrir um ramal ou uma estrada de seringa, limpar uma área para plantar, construir uma benfeitoria, etc.

Se por um lado, existem pressões de mudanças drásticas sobre a identidade extrativista, por outro, as sociedades caboclas da Amazônia têm sido culturalmente caracterizadas por um alto grau de flexibilidade e resiliência, como já foi mencionado. Nesse sentido, é possível que exista uma susceptibilidade das populações extrativistas a aceitarem, com pouca resistência, as mudanças na sua relação com atividades produtivas e aceitarem as pressões de pluriespecialização, polivalência e flexibilização dos ofícios.

Hall (2008, p. 79) coloca que:

As comunidades migrantes trazem as marcas da diáspora, da "hibridização" e da différance em sua própria constituição. Sua integração vertical a suas tradições de origem coexiste como vínculos laterais estabelecidos com outras "comunidades" de interesse, prática e aspiração, reais ou simbólicos. Os membros individuais, principalmente as gerações mais jovens, são atraídos por forças contraditórias. Muitos "estabelecem" seus próprios acordos ou os negociam dentro e fora de suas comunidades. As mulheres que respeitam as tradições de suas comunidades se sentem livres para desafiar o caráter patriarcal destas, bem como o chauvinismo da autoridade ali exercida. Outras se sentem bem, se conformando. Outras ainda, mesmo não querendo trocar identidades, insistem em seu direito individual de consentir e, quando não há consentimento, em seu direito a sair da comunidade corretamente reivindicando o apoio do sistema judiciário e de outras agências sociais para que o exercício daquele direito se torne efetivo. O mesmo acontece com a dissidência política e religiosa.

Alguns produtores já começam a se auto-atribuir a denominação de manejador, categoria de trabalho e identidade induzida pelos vários difusores, sobretudo engenheiros florestais, ou a denominação agricultor ou peão, mesmo que ainda colha castanha ou borracha; situações que reforçam o já citado fazerse (the making, em inglês) descrito por Thompson (2004). Embora essas denominações tenham ganhado força, uma boa parte dos entrevistados ao serem questionados sobre sua profissão, ainda se definem como seringueiros. A resistência aos processos de flexibilização dependeria de uma forte organização do movimento social que, como colocado acima, também está enfraquecido e precisaria de uma revitalização e articulação identitária.

A flexibilização também afeta as relações entre homens e mulheres e muda a dinâmica da unidade doméstica. Em uma análise sobre o povo Guarani/Kaiowá de Caarapó, Grubits et al (2005, p.6) coloca que "a mulher constrói e adquire uma identidade feminina Guarani/Kaiowá, enquanto o homem adquire uma identidade masculina de homem da cidade", entre outros fatores, devido ao deslocamento dos homens para as usinas de álcool ou as fazendas da região. Este exemplo propicia um interessante distanciamento para a análise de gênero: novas formas de endoculturação geradas no âmbito da flexibilização estão também produzindo novas relações entre mulheres e homens e, consequentemente, novas formas de organização do grupo familiar. De forma geral, os homens que anteriormente cortavam seringa e eram responsáveis pelo roçado perto de casa passam agora um tempo considerável nas novas atividades produtivas e nos respectivos processos de gestão (Participando de capacitações, agendas com organizações de apoio, organização das associações, reuniões, realizando pressões políticas para o licenciamento, etc...), deixando em segundo plano as atividades relacionadas à agricultura familiar. São as mulheres que, frequentemente assumem essas labores, às vezes acompanhadas pelos/as filhos/as mais velhas/os, onde geralmente é a 
mulher que passa a tomar as decisões relacionadas. Se, por um lado isso pode representar uma descentralização da tomada de decisão que empodera a mulher em alguns espaços e momentos da unidade doméstica, por outro significa também uma sobrecarga de trabalho para a mulher no âmbito familiar, como educadora e "guardiã da cultura" (GRUBITS et al 2005). Além disso, significa reforçar o vínculo do homem à renda monetária e reforçar o vínculo da mulher à economia doméstica não-monetária. Um exemplo prático desta lógica é o mesmo produtor citado que lesionou a coluna: após circular por um tempo no mercado de trabalho de serviços (economia monetária), por estar inapto para continuar no trabalho físico, abandonou a casa e a família no interior do Acre e foi morar no Estado do Pará, como assessor de manejo, adquirindo, quase absolutamente, uma identidade de "homem da cidade".

Para finalizar os exemplos de impactos da flexibilização, vale colocar que em geral, formas exaustivas de exploração da força de trabalho diminuem o tempo livre dedicado ao lazer entendido como dimensão integrante de um projeto político-pedagógico, como "tempo e espaço possível para exercício da participação, da autoconsciência, da liberdade e da igualdade, aceito como importante dimensão da educação, da ação política e da relação hegemônica, prática social determinante para a emancipação humana" (MASCARENHAS In: PADILHA, 2006, p. 80-81). Enquanto nas atividades tradicionais o seringueiro definia o ritmo de seu trabalho com mais liberdade, o envolvimento com cadeias produtivas mais complexas impõem também horários e jornadas de trabalho; no ano de 2007 a COOPERFLORESTA exerceu atividades de exploração madeireira nos fins de semana, convocando seus associados e produtores a saírem da sua jornada habitual de trabalho e no Projeto de Colonização Padre Peixoto, um tradicional futebol de domingo começou a esvaziar-se com o tempo após o inicio da exploração madeireira na área (Leonardo Lopes, observação pessoal). Em geral, atividades em larga produção também afastam a caça das colocações e esta atividade, além de ter uma importância em termos de segurança alimentar, representa também uma das atividades mais apreciadas em termos de utilização do tempo livre e diversão na floresta, tanto que ao perguntar pelo quê optariam, o manejo madeireiro ou a caça, a resposta têm sido consensual pela caça; "existe um discurso falacioso de que o ideal para as pessoas seria não trabalhar, não ter nada para fazer, viver de rendas, uma espécie de ideologia da ociosidade" (NAVARRO apud PADILHA, 2006, p. 70) - discurso que surge inicialmente com o manejo madeireiro, mas que já está bastante presente na maioria das discussões sobre mecanismos de pagamento por serviços ambientais e mecanismos de mitigação às mudanças climáticas, como créditos de carbono e REDD.

Como bem lembra Coriat (2001), o capital procura primeiro uma saída na máquina, no capital constante. No momento em que as populações tradicionais possuem os recursos naturais (ou possuem ao menos a concessão de uso desses) essa "saída" complica-se. $\mathrm{Na}$ ótica capitalista, seria mais fácil, como se ouve dizer no âmbito da gestão desses projetos, pedir às comunidades que "deitassem na rede", enquanto os profissionais do manejo (ou do clima) fazem a exploração, aumentando a escala de produção, e pagando depois a parte que lhe cabe à comunidade. A primeira vista, parece uma estratégia para simplificar as oportunidades de geração de renda. Porém, isto seria incentivar uma forma de alienação, fetichização e estranhamento na relação entre comunidade e floresta: "negar o sujeito autônomo e colocar o homem sob o controle de movimento de coisas" (...) "o processo de produção domina os homens e não os homens o processo de produção" (ALVES apud PADILHA, 2006, p. 42). Seria também instituir o arrendamento das terras/florestas para a cadeia madeireira sendo que, por um lado, "toda renda do solo é mais-valia, produto do trabalho excedente" (Marx, 2001, p. 591), e por outro, como coloca Loureiro (2006, p. 89), seria gerar “"autonomia' local, subordinada a interesses macroeconômicos descolados das necessidades objetivas das comunidades". O discurso do "deitar na rede" coloca por si próprio uma contradição entre o bem-estar comunitário e a "necessidade de desenvolvimento das forças produtivas": terceirização e aumento da escala na produção. Os projetos tornam-se bastante dúbios: afinal, o foco está de fato na conservação da natureza e na melhoria da qualidade de vida das comunidades, ou está na verdade no aumento da escala de produção 
para atender o mercado da commoditty madeira? Um "discurso falacioso", uma "ideologia da ociosidade"?

Os processos de certificação e auditorias surgem como uma forma de controle de qualidade, que em tese outorgam poder aos consumidores para agir politicamente e externalizar suas preocupações por meio do ato de compra. Os selos de qualidade, porém, não são fenômenos recentes e já no final do século XIX existiam iniciativas nesse sentido, como os selos para cigarros nos Estados Unidos (CORIAT, 2001), e desde aquele tempo já se constatam relações com o enfraquecimento das organizações de representação e com a qualidade de vida dos trabalhadores. Formas de controle de qualidade, desde o Controle Total de Qualidade, proposto na década de 50 pelo japonês Kaoru Ishikawa, até outras formas de controle mais recentes, têm sido associadas a processos de flexibilização do capital uma vez que o controle da produção fica diretamente ligado a um consumidor geralmente exigente e estas exigências recaem em uma exploração maior da força de trabalho (NEGRET, 2001); os produtos da certificação comunitária são preteridos pela certificação empresarial, uma vez que ambos competem no mesmo mercado e as empresas têm uma condição melhor de atender às exigências do consumidor. Neste sentido, a certificação surge como uma forte forma de pressão para a pluriespecialização da população residente na RESEX e do entorno, consequentemente, para uma maior flexibilização dos ofícios. Da mesma forma que projetos que visam o "aumento da escala da produção" e os projetos que visam o controle com "certificação por terceira parte" recaem na flexibilização e no aumento da taxa de exploração das populações tradicionais.

Considerando que, a premissa básica dos projetos de conservação por meio da melhora das condições de vida das populações tradicionais é que melhores condições contribuiriam para a manutenção da floresta, e considerando que, embora com maior renda monetária, a qualidade de vida decai como conseqüência da flexibilização, a RESEX Chico Mendes poderá passar (ou já está passando) por uma queda das condições de vida dos trabalhadores. Essa queda das condições de vida são então um risco para a integridade ambiental da Reserva.

Na reunião do Conselho Deliberativo da RE-
SEX Chico Mendes, realizada entre os dias 30 e 31 de outubro de 2008, quatro novas determinações foram aprovadas para compor o plano de uso, no sentido de realizar uma retomada de gestão da área protegida: a) proibição de qualquer tipo de arrendamento de pastagens; b) limitação em 30 cabeças de gado por colocação; c) proibição da venda da madeira em tora; e d) proibição do uso de máquinas terceirizadas de arraste nos manejos comunitários madeireiros, por considerar que em RESEX o manejo poderá ser somente de baixa intensidade, seguindo a Instrução Normativa 05 (IBAMA, 2006b); regra esta que, indiretamente, já limita a exploração a no máximo $10 \mathrm{~m}^{3}$ por hectare na RESEX. Todas as medidas estão correlacionadas com a flexibilização.

No dia 17 de dezembro de 2008, o Sindicato de Trabalhadores Rurais de Xapuri tornou pública uma Nota de Repudio na qual colocam que "os seringueiros não podem ser responsabilizados pela mudança do clima do planeta, este se deve a ação dos grandes pecuaristas, mineradoras e do grande capital" e que "nestes dezoito anos de criação da Reserva não existe uma política que garanta uma renda para os seringueiros viverem com dignidade exclusivamente da produção extrativista".

\section{CONCLUSÕES}

Enquanto o extrativista se apossa das terras por meio do instrumento legal RESEX, as estratégias capitalistas flexibilizam suas relações: pecuaristas e madeireiros continuam aumentando seu capital constante em relação ao capital variável, continuam o processo de desterritorialização do capital, de exploração e espoliação, trazendo novos desafios para as lutas do movimento social que continua refém das estruturas desiguais. A depender do capital, seja pecuária ou madeira, formas diferentes de flexibilização podem ser operadas. Estas variações acontecem seja quando as comunidades possuem os meios de produção (no caso a terra) ou quando não os possuem (no caso as máquinas do manejo). No caso da força de trabalho, constata-se a terceirização das relações tanto fora quanto dentro das comunidades, sendo que estas, em específico, estão desenvolvendo novas maneiras de relacionar-se com o tempo, processo concomitante 
com o desenvolvimento de novos ofícios; e mudanças nos ofícios têm acarretado mudanças na identidade, no "tradicional" e nos padrões de organização familiar e comunitária.

As certificadoras, as empresas e o governo em geral atestam e respaldam a terceirização, e conseqüentemente, ao contrário de seu discurso oficial, certificam também as estruturas de concentração de capital e aumento das desigualdades sociais. A ausência de medidas estruturais quanto à superação das estratégias capitalistas tendem a colocar comunidades e Estado uns contra os outros (vide deliberações do conselho deliberativo), e não resolvem a contradição principal, a causa da degradação ambiental e da usurpação da dignidade dos trabalhadores da floresta.

É evidente a necessidade de políticas econômicas planificadas para o sucesso do modelo das RESEX. Trata-se de abandonar iniciativas produtivistas e projetos que enfatizem a transformação das populações tradicionais em meros "mercadores da floresta"; abandonar políticas públicas que prezem pela livre-concorrência; de fortalecer políticas de controle social, com participação não necessariamente só do Estado, mas com certeza não só do mercado - um exemplo interessante são certificações socioparticipativas, que construam os mecanismos de controle junto às comunidades e outros atores sociais; de estruturar políticas que propiciem condições mínimas de preço, mercados institucionais com compras públicas, subsídios e incentivos efetivos e proporcionais aos investimentos estatais para a soja, pecuária e outras commodities, para os produtos da floresta; de valorizar iniciativas que fortaleçam as identidades relacionadas ao uso da floresta, respeitando os tempos de trabalho tradicionais. Inovar em modos de produção sustentáveis significa inovar nos meios de produção e nas formas de circulação, troca e consumo das mercadorias, e reinventar os próprios paradigmas de produção e planejamento.

Da mesma forma que surgem todos estes desafios, também surgem algumas respostas desde a própria comunidade: "Isso é sustentabilidade: cada um na sua capacidade" (Produtor do PAE Cachoeira entrevistado em 02/10/08), ou "Às vezes é melhor ganhar menos com a sua prática do que ganhar mais com a prática dos outros" (Produtor do PAE Equador entrevistado em 03/10/08). As declarações lembramnos a máxima da Crítica ao Programa de Gotha: "De cada um segundo as suas capacidades, a cada um segundo as suas necessidades". Será mais justo e eficiente se os projetos de desenvolvimento investissem em processos de produção menos complexos, em cadeias produtivas que permitam que as populações tradicionais, como os moradores da RESEX e do entorno, sejam donos dos meios de produção, não flexibilizados, e sejam senhores do seu próprio destino e do seu próprio tempo.

\section{REFERÊNCIAS}

ACRE. Zoneamento ecológico-econômico do Estado do Acre - Documento síntese $2^{a}$ Fase. Rio Branco: Governo do Estado do Acre, 2006.

ALLEGRETTI, M. H. Reservas extrativistas: Parâmetros para uma política de desenvolvimento sustentável na Amazônia. In: ARNT, R. (Ed). O destino da floresta - Reservas extrativistas e desenvolvimento sustentável na Amazônia. Rio de Janeiro: Dumará Distribuidora de Publicações, 1994. Cap 1, p. 17-47.

ALVES, G. Trabalho, subjetividade e lazer: estranhamento, fetichismo e reificação no capitalismo global. In: PADILHA, V. (Org). Dialética do lazer. São Paulo: Cortez Editora, 2006. Cap. 1. p. 19-49.

BRASIL. Lei Federal n. 9.985, de 18 de julho de 2000. Lei do Sistema Nacional de Unidades de Conservação - SNUC.

BRONDÍZIO, E. S. Intensificação agrícola, identidade econômica e invisibilidade entre pequenos produtores rurais amazônicos: caboclos e colonos numa perspectiva comparada. In: ADAMS, C., MURRIETA, R. S. S., e NEVES, W. A. (Org.). Sociedades caboclas amazônicas - Modernidade e invisibilidade. São Paulo: Annablume Editora, 2006. Cap 7. p. 195235.

BROWN, L. R. Eco-economia - Construindo uma economia para a terra. Salvador: Universidade Livre da Mata Atlântica, 2003. 
CASTELLS, M. A sociedade em rede - A era da informação. v. 1, 6 ed. São Paulo: Editora Paz e Terra, 2005.

CASTRO, F. Economia familiar cabocla na várzea do médio-baixo Amazonas. In: ADAMS, C., MURRIETA, R. S. S., e NEVES, W. A. (Org.). Sociedades caboclas amazônicas - Modernidade e invisibilidade. São Paulo: Annablume Editora. cap. 7, 2006. p. 173194.

CORIAT, B. El taller y el cronómetro - Ensayo sobre el taylorismo, el fordismo y la producción en masa. Madrid: Siglo Veintiuno de España Editores, 5 ed., 2001.

FOSTER, J. B. A ecologia de Marx: materialismo e natureza. Rio de Janeiro: Civilização Brasileira, 2005.

GOMES, C. V. A. Dynamics of land use in an Amazonian extractive reserve: the case of the Chico Mendes Extractive Reserve in Acre, Brazil. 2001. 141 p. Dissertação (Mestrado) - Universidade da Flórida, Gainesville, 2001.

GRUBITS, S., DARRAULT-HARRIS, I.; PEDROSO, M. Mulheres Indígenas: Poder e Tradição. Psicologia em Estudo, Maringá, v. 10, n. 3, p. 363-372, 2005 .

GUIMARÃES JUNIOR, I. S. Identidade, Mídia e Poder: As Redes do Autoritarismo Simbólico no Discurso da Florestania. In: SEMINÁRIO INTERNACIONAL DE COMUNICAÇÃO, 9, Grupo de Trabalho: Simulacros e (Dis) Simulações na Sociedade HiperEspetacular, 2007, Porto Alegre.

HALL, S. Da diáspora - Identidades e mediações culturais. Belo Horizonte: Editora UFMG, 2 Reimpressão Revista, 2008.

HARVEY, D. O novo imperialismo. São Paulo: Edições Loyola, $2^{\mathrm{a}}$ Edição, 2005.

HAWKEN, P., LOVINS, A. e LOVINS, L. H. Capitalismo natural - Criando a próxima revolução indus- trial. São Paulo: Editora Cultrix, 1999. 358 p.

INSTITUTO BRASILEIRO DO MEIO AMBIENTE E DOS RECURSOS NATURAIS NÃO RENOVÁVEIS - IBAMA. Diário Oficial da União, Portaria n. 28, de 18 de abril de 1995. Plano de Utilização da Reserva Extrativista Chico Mendes, 1995.

. Diário Oficial da União, Resolução n. 01, de 13 de dezembro de 2006. Plano de Manejo da Reserva Extrativista Chico Mendes, 2006a.

Diário Oficial da União, n. 238, Instrução Normativa n. 05, de 11 de dezembro de 2006. p. 155159. Procedimentos técnicos para planos de manejo florestal sustentável, 2006b.

IMAFLORA/SM, 2007. Relatório de Auditoria Anual SLIMF2006 do Manejo Florestal para: Associação dos Produtores do Projeto de Assentamento Agroextrativista do Seringal Equador (ASPPAE-SE) em Xapuri-Acre - Brasil, Relatório Institucional, Piracicaba. Disponível em: <http://www.rainforest-alliance.org/ forestry/documents/asppae-seequadorpubsum06por.pdf $>$. Acesso em 08 set. 2009.

KLEIN, N. No logo. Londres: Harper Perennial, 2005.

LIMA, D. M. A economia doméstica em Mamirauá. In: ADAMS, C., MURRIETA, R. S. S., e NEVES, W. A. (Org.). Sociedades caboclas amazônicas - Modernidade e invisibilidade. São Paulo: Annablume Editora, 2006. cap 6, p. 145-172.

LOUREIRO, C. F. B. O movimento ambientalista e o pensamento crítico: uma abordagem política. 2. ed. Rio de Janeiro: Quartet Editora \& Comunicação Ltda, 2006.

LOUREIRO, C. F. B. Pensamento crítico, tradição marxista e a questão ambiental: ampliando os debates. In: LOUREIRO, C. F. B. (Org). A questão ambiental no pensamento crítico - Natureza, trabalho e educação. Rio de Janeiro: Quartet Editora \& Comunicação Ltda, 2007. cap 1, p.13-67. 
LÖWY, M. Ecologia e socialismo. São Paulo: Cortez Editora, 2005.

LUKÁCS, G. História e consciência de classe - Estudos sobre a dialética marxista. São Paulo: Livraria Martins Fontes Editora Ltda, 2003.

MASCARENHAS, F. Em busca do ócio perdido: idealismo, panacéia e predição histórica à sombra do lazer. In: PADILHA, V. (Org). Dialética do lazer. São Paulo: Cortez Editora, 2006. cap. 3, p. 75-103.

MARX, K. El capital - Crítica de la economía política. v. 3, 2. ed. em Espanhol. Cidade do México: Fondo de Cultura Econômica, 27. Impressão, 2001.

MARX, K. Para a crítica da economia política. São Paulo: Editora Nova Cultural, Coleção Os Pensadores, 2005.

MARX, K. O capital - Crítica da economia política. v. 1, 25. ed. Rio de Janeiro: Civilização Brasileira, Livro 1, 2008.

MEDINA, G.; POKORNY, B. Avaliação financeira do manejo florestal comunitário, Belém: ProManejo, 2008.

MÉSZÁROS, I. Para além do capital - Rumo a uma teoria da transição. São Paulo: Boitempo Editorial, 2002.

O desafio e o fardo do tempo histórico. São

Paulo: Boitempo Editorial, 2007.

MMA. Amazônia - Reservas extrativistas estratégias 2010. Brasília: Edições IBAMA, 2002.

NAVARRO, V. L. Trabalho, saúde e tempo livre sob os domínios do capital. In: PADILHA, V. (Org). Dialética do lazer. São Paulo: Cortez Editora, 2006. cap. 2. p. 50-74.

NEGRET, F. Organización de los procesos de trabajo, condiciones de vida de los trabajadores y flexibilización. 2001. 215 p. Tese (Doutorado) - Departamen- to de Economia, Universidad Nacional Autónoma de México, Ciudad de México.

NOVICKI, V. Praxis: problematização consciência e participação na educação ambiental brasileira. In: LOUREIRO, C. F. B. (Org). A questão ambiental no pensamento crítico - Natureza, trabalho e educação. Rio de Janeiro: Quartet Editora \& Comunicação Ltda, 2007. cap. 4, p.135-171.

PAULA, E. A. de. (Des) Envolvimento insustentável na amazônia ocidental. Rio Branco: EDUFAC, 2005.

SCHWARTZMAN S. Mercados para produtos extrativistas da Amazônia brasileira. In: ARNT, R. (Ed). O destino da floresta - Reservas extrativistas e desenvolvimento sustentável na Amazônia. Rio de Janeiro: Dumará Distribuidora de Publicações, 1994. cap. 8, p. 247-257.

SEVÁ, F. Ambientalismo e desenvolvimento sustentável: o caso da borracha e da pecuária no Acre. 2002. 113p. Monografia (Graduação), Departamento de Economia, Universidade Federal do Acre, Rio Branco.

THOMPSON, E. P. A formação da classe operária inglesa - A árvore da liberdade. São Paulo: Editora Paz e Terra S/A, v. 1, 2004.

Sociedade \& N atureza, U berlândia, 22 (2): 373-390, ago. 2010 